\title{
Intraserotype diversity among Argentinian verocytotoxigenic Escherichia coli detected by random amplified polymorphic DNA analysis
}

\author{
Alejandra Krüger, Nora L. Padola, Alberto E. Parma \\ and Paula M. A. Lucchesi \\ Lab. Inmunoquímica y Biotecnología, Depto. Sanidad Animal y Medicina Preventiva, Fac. Cs. \\ Veterinarias, Universidad Nacional del Centro Pcia. Buenos Aires, Pinto 399 (7000), Tandil, \\ Argentina
}

Correspondence

Paula M. A. Lucchesi

paulaluc@vet.unicen.edu.ar

Received 22 September 2005 Accepted 12 January 2006

\begin{abstract}
Most cases of diarrhoea-associated haemolytic uraemic syndrome (HUS) are caused by verocytotoxin-producing Escherichia coli (VTEC). Argentina has the highest worldwide incidence of HUS, but with a lower incidence of VTEC O157: H7 serotype than non-Latin American countries. A large number of VTEC serotypes have been isolated from cattle and cattle-derived food products in Argentina. The aim of this work was to study intraserotype genetic diversity among these VTEC strains by random amplification of polymorphic DNA (RAPD). Strains were selected that belonged to the same serotype, but had been isolated from different sources (cattle and meat). Intraserotype genetic diversity was detected among strains belonging to $\mathrm{O} 20: \mathrm{H} 19, \mathrm{O} 113: \mathrm{H} 21$, $\mathrm{O} 117: \mathrm{H} 7, \mathrm{O} 157: \mathrm{H} 7, \mathrm{O} 171: \mathrm{H} 2$ and $\mathrm{O} 174: \mathrm{H} 21$, but only one RAPD profile corresponded to strains belonging to $\mathrm{O} 91: \mathrm{H} 21$, although these isolates were from different sources.
\end{abstract}

\section{INTRODUCTION}

Verocytotoxin-producing Escherichia coli (VTEC) are human pathogens that cause a wide spectrum of illness, encompassing asymptomatic infection, mild-to-moderate diarrhoea, haemorrhagic colitis, and haemolytic uraemic syndrome (HUS) (Karmali, 1989). Argentina has the highest worldwide incidence of HUS (López et al., 1998), corresponding to $10 \cdot 5$ per 100000 in children under 5 years of age (Meichtri et al., 2004). VTEC serotypes appear to differ in pathogenic potential, but the molecular basis for this is not known (Karmali, 2005). Although serotype O157:H7 has been implicated in most cases of HUS globally, there is growing concern about non-O157 serotypes of VTEC (Karmali, 2005). In Argentina, the incidence of O157: H7 is low in HUS patients compared with that of non-Latin American countries (López et al., 1998). Several other serotypes (O26: H11, O91: $\mathrm{H}-, \mathrm{O} 103: \mathrm{H}-, \mathrm{O} 111: \mathrm{H}-, \mathrm{O} 113: \mathrm{H} 21$, $\mathrm{O} 121: \mathrm{H} 19$ and $\left.\mathrm{O} 145: \mathrm{H}^{-}\right)$have also been isolated from human patients in Argentina (Guth et al., 2003).

Domestic animals, particularly bovines, appear to be the major reservoir of VTEC, and foods of animal origin are the major sources of human infection (Karmali, 1989). A large number of VTEC serotypes have been isolated from cattle and cattle-derived food products in Argentina (Parma et al., 2000; Chinen et al., 2001; Padola et al., 2002, 2004; Blanco et al., 2004; Meichtri et al., 2004). In this study, our objective

Abbreviations: RAPD, random amplification of polymorphic DNA; VTEC, verocytotoxin-producing Escherichia coli. was to characterize VTEC isolates by random amplification of polymorphic DNA (RAPD) to analyse the genetic diversity among strains belonging to the same serotype that had been isolated from both cattle and meat. This is not an epidemiological study, as strains isolated from meat are not epidemiologically linked to those isolated from cattle.

Most RAPD studies of VTEC focus on serogroup O157 (Bielaszewska et al., 1998; Hopkins \& Hilton, 2001; Tutenel et al., 2003; Kim et al., 2005). Only a few VTEC non-O157 serogroups have been analysed by RAPD: O26, O103 and O111 (Schmidt et al., 1999; Peixoto et al., 2001), and we have previously analysed isolates belonging to O145 (Padola et al., 2002). Therefore, this paper is one of the few that study intraserotype diversity by RAPD among both $\mathrm{O} 157$ and non-O157 serogroups.

\section{METHODS}

Bacterial isolates. The VTEC strains used in this study were isolated from cattle and from bovine meat, and most of them have been described previously (Parma et al., 2000; Padola et al., 2004; Blanco et al., 2004). Detection was by PCR analysis of the genes encoding verocytotoxin 1 and $2\left(v t_{1}\right.$ and $\left.v t_{2}\right)$, intimin (eae), enterohaemolysin (ehxA) and Shiga toxin-producing Escherichia coli (STEC) autoagglutinating adhesin (saa). When two or more isolates from the same sample did not differ in either one virulence factor or the serogroup, only one of them was analysed in this study. We selected strains that belonged to the same serotype but had been isolated from different sources (cattle and meat). They belonged to serotypes O20:H19 (seven isolates), O91:H21 (four isolates), O113:H21 (four isolates), O117:H7 (nine isolates), O157:H7 (six 
Table 1. VTEC isolates analysed in this study

\begin{tabular}{|c|c|c|c|}
\hline Serotype & Strain name $(\text { origin })^{\star}$ & Virulence profile $\dagger$ & RAPD profile \\
\hline \multirow[t]{7}{*}{$\mathrm{O} 20: \mathrm{H} 19$} & T 22-1 (g) & $v t_{1}^{+} v t_{2}^{+}$ & A \\
\hline & T $22-2(\mathrm{~g})$ & $v t_{1}^{+} v t_{2}^{+} e h x A^{+} s a a^{+}$ & A \\
\hline & HT 1-6 (h) & $v t_{1}^{+} v t_{2}^{+} e h x A^{+} s a a^{+}$ & B \\
\hline & AM 114-1 (a) & $v t_{1}^{+} v t_{2}^{+} e h x A^{+} \mathrm{saa}^{+}$ & $\mathrm{B}$ \\
\hline & AP 28-1 (g) & $v t_{2}^{+} e h x A^{+} \mathrm{saa}^{+}$ & B \\
\hline & FO 114 (f) & $v t_{1}^{+} v t_{2}^{+} e h x A^{+} s a a^{+}$ & B \\
\hline & HT 6-2 (h) & $v t_{2}^{+}$ & $\mathrm{C}$ \\
\hline \multirow[t]{4}{*}{ O91 : H21 } & AP 16-1 (g) & $v t_{2}^{+} e h x A^{+} \mathrm{saa}^{+}$ & $\mathrm{D}$ \\
\hline & FO 130 (f) & $v t_{2}{ }^{+} e h x A^{+} \mathrm{saa}^{+}$ & $\mathrm{D}$ \\
\hline & FO 135 (f) & $v t_{2}{ }^{+} e h x A^{+} \mathrm{saa}^{+}$ & $\mathrm{D}$ \\
\hline & HAB $14(\mathrm{~h})$ & $v t_{2}{ }^{+} e h x A^{+} s a a^{+}$ & $\mathrm{D}$ \\
\hline \multirow[t]{4}{*}{$\mathrm{O} 113: \mathrm{H} 21$} & FC 103 (f) & $v t_{2}^{+}$ & $\mathrm{E}$ \\
\hline & AP 97-3 (g) & $v t_{2}{ }^{+} e h x A^{+} s a a^{+}$ & $\mathrm{E}$ \\
\hline & BE 2-3 (e) & $v t_{2}^{+} e h x A^{+} s a a^{+}$ & $\mathrm{F}$ \\
\hline & HT 7-14 (h) & $v t_{2}{ }^{+}$ & G \\
\hline \multirow[t]{9}{*}{ O117: H7 } & FC $146(f)$ & $v t_{2}{ }^{+}$ & $\mathrm{H}$ \\
\hline & FC 149 (f) & $v t_{2}{ }^{+}$ & $\mathrm{H}$ \\
\hline & FT 156 (f) & $v t_{2}{ }^{+}$ & $\mathrm{I}$ \\
\hline & FT 161 (f) & $v t_{2}{ }^{+}$ & I \\
\hline & FG 163 (f) & $v t_{2}{ }^{+}$ & I \\
\hline & AM 214-1 (a) & $v t_{2}{ }^{+}$ & I \\
\hline & HT 1-14 (h) & $v t_{2}{ }^{+}$ & I \\
\hline & HT 2-2 (h) & $v t_{2}{ }^{+}$ & I \\
\hline & AP 32-1 (g) & $v t_{2}{ }^{+}$ & $\mathrm{J}$ \\
\hline \multirow[t]{6}{*}{ O157 : H7 } & HT 2-15 (h) & $\mathrm{vt}_{2}{ }^{+} e a e^{+} e h x A^{+}$ & K \\
\hline & FB 3 (f) & $v t_{2}{ }^{+} e a e^{+} e h x A^{+}$ & K \\
\hline & FB 80 (f) & $v t_{2}^{+} e a e^{+} e h x A^{+}$ & K \\
\hline & FB 22 (f) & $v t_{2}^{+} e a e^{+} e h x A^{+}$ & $\mathrm{L}$ \\
\hline & FB 81 (f) & $v t_{2}{ }^{+} e a e^{+} e h x A^{+}$ & $\mathrm{L}$ \\
\hline & FC O157 (f) & $v t_{2}{ }^{+} e a e^{+} e h x A^{+}$ & M \\
\hline \multirow[t]{11}{*}{$\mathrm{O} 171: \mathrm{H} 2$} & FB 27 (f) & $v t_{2}^{+}$ & $\mathrm{N}$ \\
\hline & FB 38 (f) & $v t_{2}{ }^{+}$ & $\mathrm{N}$ \\
\hline & FB 49 (f) & $v t_{2}{ }^{+}$ & $\mathrm{N}$ \\
\hline & FB 58 (f) & $v t_{2}{ }^{+}$ & $\mathrm{N}$ \\
\hline & AM 174-1 (a) & $v t_{2}{ }^{+}$ & $\mathrm{N}$ \\
\hline & AM 200-2 (a) & $v t_{2}{ }^{+}$ & $\mathrm{N}$ \\
\hline & AM 203-3 (a) & $v t_{2}{ }^{+}$ & $\mathrm{N}$ \\
\hline & AM 217-1 (a) & $v t_{2}{ }^{+}$ & $\mathrm{N}$ \\
\hline & FO 140 (f) & $v t_{2}{ }^{+}$ & $\mathrm{O}$ \\
\hline & CM 20-7 (m) & $v t_{2}{ }^{+}$ & $\mathrm{O}$ \\
\hline & FB $8(f)$ & $v t_{2}{ }^{+}$ & $\mathrm{P}$ \\
\hline \multirow[t]{9}{*}{$\mathrm{O} 174: \mathrm{H} 21$} & FC 101 (f) & $v t_{2}{ }^{+}$ & Q \\
\hline & AM 174-2 (a) & $v t_{2}{ }^{+}$ & Q \\
\hline & AM 170-3 (a) & $v t_{1}^{+} v t_{2}^{+} e h x A^{+}$ & Q \\
\hline & T 186-3 (g) & $v t_{2}{ }^{+}$ & Q \\
\hline & FB 10 (f) & $v t_{2}{ }^{+}$ & $\mathrm{R}$ \\
\hline & FB 33 (f) & $v t_{2}{ }^{+}$ & $\mathrm{R}$ \\
\hline & FO 122 (f) & $v t_{2}{ }^{+}$ & $\mathrm{R}$ \\
\hline & AM 178-2 (a) & $v t_{2}{ }^{+}$ & $\mathrm{R}$ \\
\hline & CM 25-12 (m) & $v t_{2}{ }^{+}$ & $\mathrm{R}$ \\
\hline
\end{tabular}

${ }^{\star}$ Origin: g, grazing cattle; f, cattle in feedlot; h, hamburger; a, cattle at abattoir; m, minced meat; e, evisceration tray (at abattoir).

$\dagger$ Previously determined by monoplex PCR assays (Parma et al., 2000; Padola et al., 2004) and confirmed in this study by multiplex PCR (Paton \& Paton, 2002). 
isolates), $\mathrm{O} 171: \mathrm{H} 2$ (11 isolates) and $\mathrm{O} 174: \mathrm{H} 21$ (nine isolates), and are described in Table 1 . All E. coli strains were routinely grown in Luria-Bertani (LB) broth at $37^{\circ} \mathrm{C}$ and stored at $-70{ }^{\circ} \mathrm{C}$ with $20 \%$ $(\mathrm{v} / \mathrm{v})$ glycerol.

RAPD fingerprinting. Template preparation and PCR amplification with primer M13 (Birch et al., 1996) were performed as described previously (Padola et al., 2002), with one modification: the thermal cycler was programmed with maximum $\left(60^{\circ} \mathrm{C} \mathrm{min}{ }^{-1}\right)$ heating/cooling rates between steps. Reproducibility of the banding patterns was checked by performing the reactions at least twice using different DNA preparations.

Reaction products $(12.5 \mu \mathrm{l})$ were analysed in a $1.8 \%$ agarose gel with ethidium bromide. After photography, DNA fingerprints were compared visually, and each RAPD profile was defined by the presence or absence of bands at particular positions on the gel. Patterns were considered different when at least one polymorphic band could be detected.

\section{RESULTS AND DISCUSSION}

RAPD analysis with primer M13 revealed intraserotypespecific variations among VTEC isolates belonging to serotypes O20:H19, O113:H21, O117:H7, O157:H7, $\mathrm{O} 171: \mathrm{H} 2$ and $\mathrm{O} 174: \mathrm{H} 21$. Bands ranged from $0 \cdot 4 \mathrm{~kb}$ to more than $1.5 \mathrm{~kb}$ in size.

Three RAPD profiles were detected among seven strains of serotype O20:H19 (Fig. 1a). Profile A was shared between two strains isolated from grazing cattle. Profile B corresponded to isolates from cattle grazing on pasture, grain-fed cattle and cattle at abattoir before slaughter, and from hamburger (one of each), and profile $\mathrm{C}$ corresponded to an isolate from hamburger (Table 1).

Only one profile was detected among four strains of serotype O91: $\mathrm{H} 21$, one isolated from grazing cattle, two from grainfed cattle, and one from hamburger (Fig. 1b, Table 1). All these isolates shared the same virulence profile $\left(v t_{2}{ }^{+} e h x A^{+}\right.$ $\left.s a a^{+}\right)$.

Three profiles were detected among the four isolates of serotype O113: H21 (Fig. 1c). Profile E was shared between two strains, one from one animal in a feedlot and one from an animal grazing on pasture (one from each); profile $\mathrm{F}$ corresponded to a strain isolated from an evisceration tray in an abattoir, and profile $\mathrm{G}$ to an isolate from hamburger (Table 1).

Nine isolates of serotype $\mathrm{O} 117: \mathrm{H} 7$, all sharing the same virulence profile $\left(\mathrm{vt}_{2}^{+}\right)$, were grouped in three profiles (Fig. 1d). Two isolates from the same feedlot corresponded to profile $\mathrm{H}$; three isolates from two different feedlots, one from an animal at abattoir, and two from hamburgers were all profile I, while profile $\mathrm{J}$ was represented by only one isolate (from an animal grazing on pasture) (Table 1). All these profiles were very similar, and only differed in one or two bands. (a)

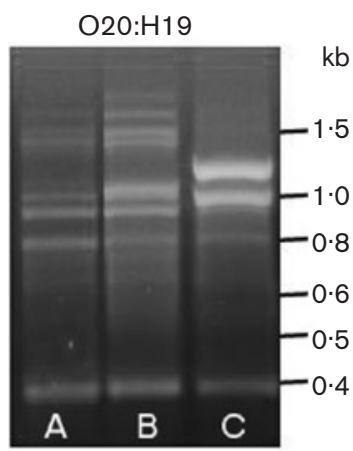

(e)

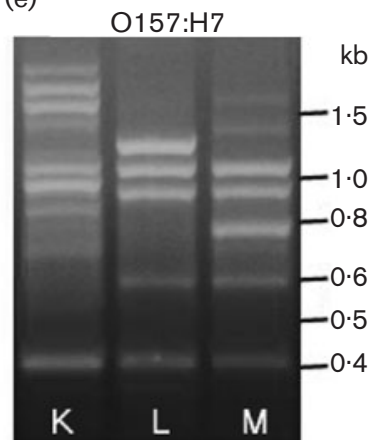

(b)

$\mathrm{kb}$

\section{$\cdot 5$}

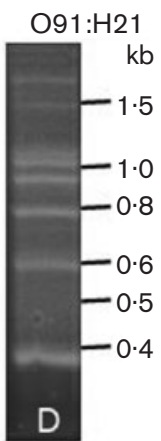

\section{s}

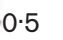

. 
Six isolates of serotype O157: $\mathrm{H} 7$ that shared the same virulence profile $\left(v t_{2}^{+} e a e^{+} e h x A^{+}\right)$belonged to three RAPD profiles (Fig. 1e). Three isolates corresponded to profile $\mathrm{K}$ (two from one feedlot and the other from hamburger), two to profile L (two isolates from the same feedlot), and a single strain from another feedlot to profile M (Table 1). Strains isolated from grain-fed cattle which belonged to profiles $\mathrm{K}$ and $\mathrm{L}$ corresponded to animals from the same feedlot.

Three RAPD profiles were found among 11 isolates of serotype $\mathrm{O} 171: \mathrm{H} 2$, all of which shared the same virulence profile $\left(v t_{2}{ }^{+}\right)$(Fig. 1f, Table 1). Profile $\mathrm{N}$ was the most common, as it was represented by eight isolates (four from animals from one feedlot and the others from animals at an abattoir). Two strains, one from a feedlot and the other from minced meat, corresponded to profile O. Profile $\mathrm{P}$ was represented by a single strain, isolated from a feedlot. Among strains isolated from animals in one feedlot, two similar profiles were found: profile $\mathrm{N}$, which corresponded to four isolates, and profile P.

Two very similar profiles, with only a one-band difference, were present among nine isolates of serotype O174: $\mathrm{H} 21$ (Fig. 1g). Four strains corresponded to profile Q (two were abattoir-collected, one was from a grain-fed animal and the other from a grazing animal). Profile $\mathrm{R}$ was shared by five isolates: three from two feedlots, one from an animal at an abattoir, and one from minced meat. All these isolates shared the same virulence profile $\left(v_{2}{ }^{+}\right)$, except for one isolate from an animal at an abattoir which corresponded to profile $\mathrm{Q}$ and was $v t_{1}{ }^{+} v t_{2}{ }^{+} e h x A^{+}$(Table 1). This was one of the few situations in which some strains shared the same RAPD profile although presenting a different virulence pattern.

Although some rapid PCR-based methods, such as those based on randomly amplified fragments (RAPD), or repetitive element PCR (Rep-PCR), may not give sufficient discrimination as a consequence of the highly clonal nature of VTEC O157 (Willshaw et al., 2001), we were able to find three different RAPD profiles among six strains belonging to serotype O157:H7.

Few studies have characterized non-O157 VTEC strains by RAPD fingerprinting. Kumar et al. (2001) characterized isolates from fish, clam and water, and Khan et al. (2002) studied strains isolated from human stool samples, cow stool samples, and beef samples in India; however, in both studies, strains were not serotyped. Schmidt et al. (1999) analysed RAPD patterns of 33 non-O157 VTEC and demonstrated three larger clusters, consisting of isolates belonging to serogroups $\mathrm{O} 26, \mathrm{O} 103$ and $\mathrm{O} 111$.

Our study compares VTEC strains belonging to several serotypes and successfully applies the RAPD technique to study the intraserotype genetic diversity among them. Some isolates, although previously regarded as homogeneous according to their virulence profile, showed different RAPD profiles. The only exception was the group of strains belonging to serotype $\mathrm{O} 91: \mathrm{H} 21$, which could not be differentiated by RAPD. This could indicate clonality among strains belonging to this serotype or the inability of primer M13 to differentiate them.

Interestingly, in a preliminary study, two human O157 : H7 isolates analysed by this technique showed two new profiles, different from those found among the six O157 : H7 strains studied here (data not shown).

In conclusion, the diversity found in many serotypes may be useful for future epidemiological studies of VTEC strains, of both $\mathrm{O} 157$ and non-O157 serogroups, and this could also be extended to VTEC strains isolated from humans. The methodology used in this study constitutes a satisfactory tool to discriminate VTEC belonging to several serotypes, and can be applied to epidemiologically linked isolates from food and humans, making it possible to identify a chain of transmission.

\section{ACKNOWLEDGEMENTS}

The authors thank M. R. Ortiz for her technical assistance. This work was supported by grants from the Comisión de Investigaciones Científicas-Gobierno Pcia. Buenos Aires (CIC), Fondo para la Investigación Científica y Tecnológica (FONCyT) and Secretaría de Ciencia y Tecnología-Universidad Nacional del Centro de la Provincia de Buenos Aires (SECyT-UNICEN). P.M.A. L. is a member of the Research Career of the Consejo Nacional de Investigaciones Científicas y Técnicas (CONICET). A. E. P. is a member of the Research Career of CIC. A. K. is a holder of a fellowship from CONICET.

\section{REFERENCES}

Bielaszewska, M., Schmidt, H., Karmali, M. A., Khakhria, R., Janda, J. \& Karch, H. (1998). Isolation and characterization of sorbitolfermenting Shiga toxin (verocytotoxin)-producing Escherichia coli O157:H- strains in the Czech Republic. J Clin Microbiol 36, 2135-2137.

Birch, M., Denning, D. W. \& Law, D. (1996). Rapid genotyping of Escherichia coli $\mathrm{O} 157$ isolates by random amplification of polymorphic DNA. Eur J Clin Microbiol Infect Dis 15, 297-302.

Blanco, M., Padola, N. L., Krüger, A. \& 11 other authors (2004). Virulence genes and intimin types of Shiga-toxin-producing Escherichia coli isolated from cattle and beef products in Argentina. Int Microbiol 7, 269-276.

Chinen, I., Tanaro, J. D., Miliwebsky, E. \& 7 other authors (2001). Isolation and characterization of Escherichia coli O157:H7 from retail meats in Argentina. J Food Prot 64, 1346-1351.

Guth, B. E. C., Chinen, I., Miliwebsky, E., Cerqueira, A. M. F., Chillemi, G., Andrade, J. R. C., Baschkier, A. \& Rivas, M. (2003). Serotypes and Shiga toxin genotypes among Escherichia coli isolated from animals and food in Argentina and Brazil. Vet Microbiol 92, 335-349.

Hopkins, K. L. \& Hilton, A. C. (2001). Restriction endonuclease analysis of RAPD-PCR amplicons derived from Shiga-like toxinproducing Escherichia coli O157 isolates. J Med Microbiol 50, 90-95.

Karmali, M. A. (1989). Infection by verocytotoxin-producing Escherichia coli. Clin Microbiol Rev 2, 15-38. 
Karmali, M. A. (2005). Use of comparative genomics as a tool to assess the clinical and public health significance of emerging Shiga toxin-producing Escherichia coli serotypes. Meat Science 71, 62-71.

Khan, A., Das, S. C., Ramamurthy, T., Sikdar, A., Khanam, J., Yamasaki, S., Takeda, Y. \& Nair, G. B. (2002). Antibiotic resistance, virulence gene, and molecular profiles of Shiga toxin-producing Escherichia coli isolates from diverse sources in Calcutta, India. J Clin Microbiol 40, 2009-2015.

Kim, J. Y., Kim, S. H., Kwon, N. H. \& 8 other authors (2005). Isolation and identification of Escherichia coli O157:H7 using different detection methods and molecular determination by multiplex PCR and RAPD. J Vet Sci 6, 7-19.

Kumar, H. S., Otta, S. K., Karunasagar, I. \& Karunasagar, I. (2001). Detection of Shiga-toxigenic Escherichia coli (STEC) in fresh seafood and meat marketed in Mangalore, India by PCR. Lett Appl Microbiol 33, 334-338.

López, E. L., Contrini, M. M. \& De Rosa, M. F. (1998). Epidemiology of Shiga toxin-producing Escherichia coli in South America. In Escherichia coli O157:H7 and other Shiga Toxin-Producing E. coli Strains, pp. 30-37. Edited by J. B. Kaper \& A. D. O’Brien. Washington, DC: American Society for Microbiology.

Meichtri, L., Miliwebsky, E., Gioffré, A. \& 8 other authors (2004). Shiga toxin-producing Escherichia coli in healthy young beef steers from Argentina: prevalence and virulence properties. Int J Food Microbiol 96, 189-198.

Padola, N. L., Sanz, M. E., Lucchesi, P. M. A., Blanco, J. E., Blanco, J., Blanco, M., Etcheverría, A. I., Arroyo, G. H. \& Parma, A. E. (2002). First isolation of the enterohaemorrhagic Escherichia coli O145: H- from cattle in feedlot in Argentina. BMC Microbiol 2, 6.
Padola, N. L., Sanz, M. E., Blanco, J. E., Blanco, M., Blanco, J., Etcheverría, A. I., Arroyo, G. H., Usera, M. A. \& Parma, A. E. (2004). Serotypes and virulence genes of bovine Shigatoxigenic Escherichia coli (STEC) isolated from a feedlot in Argentina. Vet Microbiol 100, 3-9.

Parma, A. E., Sanz, M. E., Blanco, J. E., Blanco, J., Viñas, M. R., Blanco, M., Padola, N. L. \& Etcheverría, A. (2000). Virulence genotypes and serotypes of verotoxigenic Escherichia coli isolated from cattle and foods in Argentina. Importance in public health. Eur J Epidemiol 16, 757-762.

Paton, A. W. \& Paton, J. C. (2002). Direct detection and characterization of Shiga toxigenic Escherichia coli by multiplex PCR for st $\mathrm{x}_{1}$, st $\mathrm{x}_{2}$, eae, ehxA, and saa. J Clin Microbiol 40, 271-274.

Peixoto, J. C. C., Bando, S. Y., Ordoñez, J. A. G., Botelho, B. A., Trabulsi, L. R. \& Moreira-Filho, C. A. (2001). Genetic differences between Escherichia coli O26 strains isolated in Brazil and in other countries. FEMS Microbiol Lett 196, 239-244.

Schmidt, H., Geitz, C., Tarr, P. I., Frosch, M. \& Karch, H. (1999). Non-O157:H7 pathogenic Shiga toxin-producing Escherichia coli: phenotypic and genetic profiling of virulence traits and evidence for clonality. J Infect Dis 179, 115-123.

Tutenel, A. V., Pierard, D., Van Hoof, J., Cornelis, M. \& De Zutter, L. (2003). Isolation and molecular characterization of Escherichia coli O157 isolated from cattle, pigs and chickens at slaughter. Int J Food Microbiol 84, 63-69.

Willshaw, G. A., Smith, H. R., Cheasty, T. \& O'Brien, S. J. (2001). Use of strain typing to provide evidence for specific interventions in the transmission of VTEC O157 infections. Int J Food Microbiol 66, 39-46. 